\title{
Pulverized Mangifera Indica (mango) Seed kernel Mitigated Monosodium Glutamate-Intoxicated rats' Kidney Histology and Bio-functions
}

\author{
Anthony Cemaluk C Egbuonu* and Sandra 0 Oriji \\ Department of Biochemistry, College of Natural Sciences, Michael Okpara University of Agriculture Umudike, Abia State, Nigeria
}

\begin{abstract}
Received: February 03,2017; Accepted: March 14,2017; Published: March 21, 2017
*Corresponding author: Anthony Cemaluk C Egbuonu, Ph.D, Associate Professor, Department of Biochemistry, Michael Okpara University of Agriculture Umudike, Abia State, Nigeria, Tel: +23480-3636-6565; E-mail: tonycemalukegbuonu@yahoo.com; egbuonu.anthony@mouau.edu.ng
\end{abstract}

\begin{abstract}
MonoSodium Glutamate (MSG), used as a flavor enhancing food additive, may not be indicated on the label which could result to its inadvertent use and abuse with possible adverse effects in especially MSG sensitive individuals. The study evaluated some minerals and antioxidant vitamins in pulverized Mangifera indica seed kernel, and the effects of the crude ethanol extract of the pulverized M. indica seed kernel on monosodium glutamate (MSG)-intoxicated rats' kidney using standard protocols. Sodium $(390.96 \mathrm{mg} / 100 \mathrm{~g})$ followed by vitamin C $(377.66 \mathrm{mg} / 100 \mathrm{~g})$ were higher $(\mathrm{p}<0.05)$ than the other determined minerals and antioxidant vitamins, respectively, in the M. indica seed kernel. Apart from the MSG group, the serum concentration of urea, albumin and creatinine were higher $(\mathrm{p}<0.05)$ in the extract group than in the control and MSG + high extract groups. Changes in the kidney histology of rats in the extract group were milder than in the MSG group and were comparable with those in the control. The study confirmed a definite MSG-intoxication of the kidney whereas M. indica seed kernel containing high sodium and vitamin C dose dependently mitigated the MSG-intoxication, on the rats' kidney. Further studies are warranted to determine the interactive role(s) of sodium and vitamin C in the mango seed kernel on MSG-intoxicated rats' kidney. Harnessing such studies could result to beneficial use of mango seed kernel in diet and drugs thereby reducing the hitherto waste status.
\end{abstract}

Keywords: Mangifera Indica Seed Kernel; MSG-Intoxication; Kidney Histology; Antioxidant Vitamins; Sodium

\section{Introduction}

Monosodium Glutamate (MSG) is used the world over as a unique flavor enhancing food additive [1] but may not be indicated on the label [2,3] which could result to inadvertent use and abuse with possible adverse effects in especially MSG sensitive individuals. The manufacturers of MSG maintained that it is safe for human consumption [4]. On the contrary, various research reports indicated monosodium glutamate-induced toxic influences in animals [5-8]. The mechanism of MSG intoxication is not fully known. However, since MSG is catabolyzed to glutamate, sodium and water [9], any or a combination of these catabolic products could be responsible for MSG intoxication in animals.

Mango is a very common tropical fruit-bearing plant that belongs to the genus Mangifera [10] and family Anacardiaceae [11]. Mango has varied health benefits associated with its various parts [11] and attributable to its varied phyto-constituent. For instance, mangiferin a phytoconstituent of mango had antidiabetic activity in experimental animals [12]. Hence mango is of immense economic importance [10] and in particular, the mango fruit is extensively exploited for food, juice, flavor, fragrance and color [13]. As a consequence of the varied uses of mango fruit, mango seed that constitutes approximately $50 \%$ of the total weight of mango fruit is generated as waste [14]. The disposal of such waste could contribute to environmental problems. However, mango seed could offer nutritional benefits because of its high carbohydrate and oil contents [13] as well as minerals and vitamins $[15,16]$. In addition, mango seed could be useful as a therapeutic agent or as a drug. Dried and pulverized M. indica seed has been used in ethnomedication for managing diarrhea [17]. Essentially, M. indica seed is oblong-shaped and is made up of a stony endocarp that covers the soft kernel. The M. indica kernel may constitute up to $75 \%$ of the seed and $20 \%$ of the fruit [14]. The M. indica seed kernel, usually discarded along with the seed after consuming the fleshy part of the fruit, could serve dietary and pharmacologic purposes, warranting this study.

The kidneys are one of the major organs that function to remove toxic metabolites and waste products from the blood and to maintain fluid and electrolytes balance in the body [6]. Thus, the kidneys play a vital role in the elimination of many metabolic waste products resulting from many xenobiotics, including MSG. And, any damage to the kidney could adversely affect the normal functioning of the body. It is worthwhile investigating the influence of M. indica seed kernel on MSG-induced toxicity on the kidney. Thus, this study investigated some minerals and antioxidant vitamins in Mangifera indica (mango) seed kernel and the effects of the ethanol extract of the seed kernel on the kidney 
histology and some bio-functions of normal and monosodium glutamate (MSG)-challenged rats.

\section{Experimental}

\section{Plant material and extract}

This study was conducted between June and August, 2016. Fresh mango fruits collected from a particular mango tree were purchased in June, 2016 at Orie ugba, a fruit and foodstuff market in Umuahia, Abia state. The mango fruits were identified and authenticated as Mangifera indica (German variety) by a taxonomist in the department of Plant Science and Biotechnology, Michael Okpara University of Agriculture Umudike, Nigeria.

The German variety of mango fruits was thoroughly washed with tap water. The fleshy part of each fruits was removed to obtain the seed stones which were sun-dried for three days. The sun-dried seed stones were carefully cut with clean table knife to remove the stony seed coat and obtain the seed kernels. The kernels thus obtained were chopped with home choice knife into bits and sun-dried for one week (seven days). The dried mango seed kernels were pulverized using Arthur Thomas Laboratory Mill, Crypto Model, USA. Two hundred grams (200 g) of the pulverized mango seed kernel was extracted with $800 \mathrm{ml}$ of 98 $\%$ ethanol as solvent as described earlier [18]. The resulting extract was centrifuged and filtered through Whatman number one filter paper to obtain the filtrate which was allowed to evaporate to dryness using a rotary evaporator maintained at 40 ${ }^{\circ} \mathrm{C}$. An approximate value of $34 \mathrm{~g}$ was obtained and was stored in a refrigerator at $4{ }^{\circ} \mathrm{C}$ until used.

\section{Chemicals and reagents}

A commercially available brand of MSG (99.9\% purity) used in this study was procured from Ubani market, a daily food condiments market in Umuahia, south east Nigeria. Ethanol, formalin, picric acid, Bouyer's reagent, chloroform, ammonia, sodium hypochlorite, phenol, sodium nitroprusside, sodium hydroxide, urea, sodium borate, oxalic acid, trichloroacetic acid, ferric chloride, tetraoxo sulphate VI acid, perchloric acid and all chemicals were procured from the chemical store of the department of Biochemistry, Michael Okpara University of Agriculture as certified analytical grade and were used without further purification.

\section{Animals}

Twenty adult male albino rats (weight range, $104-170 \mathrm{~g}$ ) used in this study were procured from the animal house of the Faculty of Biological Sciences, University of Nigeria, Nsukka. The rats were acclimatized for 2 weeks and randomized (based on weight) to five groups with sample size of four rats. The animals were housed in clean and dry iron cages at room temperature under standard conditions (temperature $25 \pm 2{ }^{\circ} \mathrm{c}$, relative humidity 45-55\%) and were maintained a 12 hrs light-dark cycle. The animals were fed with normal feed (vital feed, Jos Nigeria) and clean water ad libitium during acclimatization and throughout the exposure duration.

Rats in the control group were sham-dosed with distilled water (without either the extract or MSG) while rats in the MSG group were fed intoxicating dose (8 $\mathrm{g} / \mathrm{kg}$ body weight) of MSG according to Mariyamma et al. [8]. Rats in the extract group were fed mango seed kernel extract at $300 \mathrm{mg} / \mathrm{kg}$ body weight while rats in the MSG + low extract group were concomitantly fed the mango seed kernel extract ( $200 \mathrm{mg} / \mathrm{kg}$ body weight) and intoxicating dose of MSG ( $8 \mathrm{~g} / \mathrm{kg}$ body weight) whereas rats in the MSG + high extract group were co-administered $400 \mathrm{mg} / \mathrm{kg}$ body weight of the mango seed kernel extract and intoxicating dose of MSG ( $8 \mathrm{~g} / \mathrm{kg}$ body weight). The exposure was per oral and daily for 14 days. Rats in all the groups including the control were housed at $25^{\circ} \mathrm{C}$ in individual stainless steel cages under normal daylight/dark cycle and humid tropical conditions. The rats were allowed free access to rat feed and tap water and generally received humane care throughout the duration of the experiment in accordance with the guidelines of the National Institute of Health (NIH), USA for ethical treatment of laboratory animals as sought and approved by the Ethical Committees of the Department of Biochemistry and College of Natural Sciences, Michael Okpara University of Agriculture Umudike, Nigeria.

After 2 weeks exposure, the rats were sacrificed the next day after overnight fast by cardiac puncture technique [19-21] and the blood sample of the respective rats was collected individually into clean polystyrene tubes. The blood samples thus collected were respectively centrifuged at $3000 \mathrm{rpm}$ for 10 minutes. The resultant sera were respectively collected into polystyrene tubes and stored in deep freezer for the determination of serum creatinine, urea and albumin concentrations.

\section{Determination of the antioxidant vitamins ( $A, C$ and $E$ )}

Vitamin A was determined by the spectrophotometric method described earlier [22, 23]. whereas vitamin C (ascorbic acid) was determined by the method described by Okwu and Josiah [24]. Vitamin $\mathrm{E}$ in the M. indica seed kernel was determined by the method of Pearson [25]. Triplicate determinations were carried out and the mean calculated.

\section{Determination of minerals (zinc, iron, sodium)}

Sodium ( $\mathrm{Na}$ ), zinc ( $\mathrm{Zn}$ ) and iron (Fe) in the M. indica seed kernel were variously determined according to the methods described by the Association of Analytical Chemists [26] Triplicate determinations were carried out and the mean calculated.

\section{Determination of serum urea concentration}

Urea concentration was determined using urease Berthelot according to the method of Fawcett and Scott [27]. This method was based on the principle that ammonia (from the urease catalyzed hydrolysis of urea to ammonia and carbon dioxide) is converted to coloured indophenols blue in the presence of sodium nitroferricyanide-phenol and hypochlorite reagents. The absorbance of the indophenols blue was read with a spectrophotometer (Jenway Digital Spectrophotometer, Model 6320D, manufactured by Jenway Equipment Company, France) set at $625 \mathrm{~nm}$.

\section{Determination of serum creatinine concentration}

Creatinine concentration in the rats' serum was determined by the Direct Endpoint method according to Henry [28]. This was based on the principle that creatinine reacts with picric acid in 
alkaline conditions to form a coloured complex which absorbs at $510 \mathrm{~nm}$. The intensity of the colour formed is proportional to the creatinine concentration in the sample and is measured with a spectrophotometer.

\section{Determination of serum albumin concentration}

Albumin concentration in the rats' serum was determined using Bromocresol Green (BCG) according to the method of Doumas et al. [29]. This was based on the principle that serum albumin binds to the indicator 3,3',5,5,-tetrabromo-mcresolsulphonephthelein (bromocresol green, BCG) to form the albumin-BCG-complex that absorbs maximally at $578 \mathrm{~nm}$. The absorbance as measured with a spectrophotometer is directly proportional to the concentration of albumin in the sample.

\section{Histopathological examination of the kidney sections}

On sacrifice, sections of the rats' kidneys collected for histopathological examination were fixed in $10 \%$ phosphate buffered formalin for 48 hours, trimmed, dehydrated in 4 grades of alcohol (70\%, $80 \%, 90 \%$ and $100 \%$ or absolute alcohol) cleared in 3 grades of xylene and embedded in molten wax. On solidifying, the blocks were sectioned into $5 \mu \mathrm{m}$ thickness with a rotary microtome, floated in water bathe and incubated at $60{ }^{\circ} \mathrm{C}$ for 30 minutes. The $5 \mu \mathrm{m}$ thick kidney sections were subsequently cleared in 3 grades of xylene and rehydrated in 3 grades of alcohol (90\%, $80 \%$ and $70 \%)$. The sections were then stained with Hematoxylin for 15 minutes and blued (stained blue) with ammonium chloride. Differentiation was done with $1 \%$ acid alcohol before counterstaining with Eosin. Permanent mounts were made on degreased glass slides using a permanent DPX mountant (Model 44581, Sigma-Aldrich, United Kingdom)

The prepared slides were examined with a Motic ${ }^{\mathrm{TM}}$ compound light microscope at various magnifications $(\mathrm{x} 4, \mathrm{x} 10$ and $\mathrm{x} 40)$ of the objective lenses. The photomicrographs were taken using a Motic $^{\text {TM }} 9.0$ megapixels microscope camera at x100 and x 400 magnifications.

\section{Statistical analysis}

All numerical data collected were analyzed by one way analysis of variance (ANOVA) using the statistical package for Social Science (SPSS version 17; SPSS Inc., chicago.IL.,USA). Result were presented as means \pm standard error of the mean (Mean \pm SEM) at $95 \%$ significance level $(\mathrm{p}<0.05)$.

\section{Results}

The result of some minerals and antioxidant vitamins (mg/ $100 \mathrm{~g}$ ) in the pulverized M. indica seed kernel was shown on Table 1 and revealed that sodium (390.96 mg/100 g) was higher $(\mathrm{p}<0.05)$ than the other determined minerals followed by zinc $(202.19 \pm 6.29)$ and iron $(90.66 \pm 18.76)$. However, vitamin C $(377.66 \mathrm{mg} / 100 \mathrm{~g})$ was higher $(\mathrm{p}<0.05)$ than the other determined antioxidant vitamins in the M. indica seed kernel followed by vitamin A $(18.94 \pm 7.19 \mathrm{mg} / 100 \mathrm{~g})$ while the least was vitamin E $(2.27 \pm 0.25 \mathrm{mg} / 100 \mathrm{~g})$. Furthermore, out of the determined mineral and antioxidant vitamins, sodium was highest followed by vitamin C, zinc, iron and vitamin A while the least was vitamin $\mathrm{E}$.
As shown on Table 2, the urea concentration in the rats exposed to MSG alone was higher $(\mathrm{p}<0.05)$ than that in the control and in the other groups while the urea concentration in the rats exposed to the extract alone was higher $(\mathrm{p}<0.05)$ than that in the control and in the rats exposed to MSG together with higher extract concentration. The observation relative to the control was highest $(70.74 \%)$ in the rats exposed to MSG alone and least $(18.02 \%)$ in the rats exposed to MSG together with highest concentration of the extract. The observed change relative to the MSG group was highest in rats in the control group (41.439\%) followed by those in the MSG + highest extract group (30.88\%).

The result as shown on Table 3 revealed that the serum albumin concentration in the rats exposed to MSG alone was higher $(\mathrm{p}<0.05)$ than that in the control and in the other groups while the albumin concentration in the rats exposed to the extract alone was higher $(\mathrm{p}<0.05)$ than that in the control and in the rats exposed to MSG together with higher extract concentration. The observation relative to the control was highest (45.56\%) in the rats exposed to MSG alone and least (10.03\%) but reversed by $12.03 \%$ in the rats exposed to MSG together with low and highest concentration of the extract, respectively. The observed change

\begin{tabular}{|c|c|c|}
\hline & Minerals/Vitamins & $\begin{array}{c}\text { Concentration } \\
(\mathrm{mg} / \mathbf{1 0 0} \mathrm{g})\end{array}$ \\
\hline \multirow[t]{3}{*}{ Some minerals } & Sodium (Na) & $390.96 \pm 0.71$ \\
\hline & Zinc (Zn) & $202.19 \pm 6.29$ \\
\hline & Iron $(\mathrm{Fe})$ & $90.66 \pm 18.76$ \\
\hline \multirow[t]{3}{*}{ Antioxidant vitamins } & Vitamin C & $377.66 \pm 3.05$ \\
\hline & Vitamin A & $18.94 \pm 7.19$ \\
\hline & Vitamin E & $2.27 \pm 0.25$ \\
\hline
\end{tabular}

Value presented as mean \pm SEM of triplicate determinations. Significant difference at $\mathrm{p}<0.05$

Table 2: Effect of $M$. indica (mango) seed kernel extract on the serum urea concentration $(\mathrm{mmol} / \mathrm{l})$ of normal and monosodium glutamate-intoxicated rats

\begin{tabular}{|c|c|c|c|}
\hline Groups & Urea (mmol/l) & $\begin{array}{c}\text { Change } \\
\text { relative to } \\
\text { the Control } \\
(\%)\end{array}$ & $\begin{array}{c}\text { Change } \\
\text { relative to } \\
\text { MSG group } \\
(\%)\end{array}$ \\
\hline $\begin{array}{c}\text { Control } \\
\text { (distilled water } 2 \mathrm{ml} / \mathrm{kg} \\
\text { b.w) }\end{array}$ & 35.85 & 0 & -41.43 \\
\hline MSG (8 g/kg b.w) & $61.21 \pm 0.70$ & 70.74 & 0 \\
\hline Extract $(300 \mathrm{mg} / \mathrm{kg}$ b.w) & $49.27 \pm 0.74$ & +37.43 & -19.51 \\
\hline $\begin{array}{c}\text { MSG (8 g/kg b.w })+ \text { Extract } \\
200 \mathrm{mg} / \mathrm{kg} \mathrm{b.w})\end{array}$ & $53.21 \pm 0.60$ & +48.42 & -13.07 \\
\hline $\begin{array}{c}\text { MSG (8 g/kg b.w ) + Extract } \\
400 \mathrm{mg} / \mathrm{kg} \mathrm{b.w})\end{array}$ & $42.31 \pm 1.09$ & +18.02 & -30.88 \\
\hline
\end{tabular}

Value presented as mean \pm SEM of sample size, $n=4$ rats. + denotes higher by; - denotes lower by. Significant difference at $\mathrm{p}<0.05$ 
relative to the MSG group was highest in rats in the MSG + highest extract group (39.57\%) followed by those in the control group (31.29\%).

As shown on Table 4, the serum creatinine concentration in the rats exposed to MSG alone was higher $(\mathrm{p}<0.05)$ than that in the control and in the other groups while the creatinine concentration in the rats exposed to the extract alone was higher $(\mathrm{p}<0.05)$ than that in the control but lower than that in the rats exposed to MSG together with either low or high extract concentration. The observation relative to the control was highest (66.67\%) in the rats exposed to MSG alone and least (25.76) in the rats exposed to MSG together with highest concentration of the extract. The observed change relative to the MSG group was highest in rats in the control (40.00\%) followed by those in the MSG + highest extract group $(25.55 \%)$.

Effect of M. indica (mango) seed kernel extract on the kidney histology of normal and monosodium glutamate-intoxicated rats

Table 3: Effect of M. indica (mango) seed kernel extract on the serum albumin concentration ( $\mathrm{mmol} / \mathrm{l}$ ) of normal and monosodium glutamateintoxicated rats

\begin{tabular}{|c|c|c|c|}
\hline Groups & $\begin{array}{l}\text { Albumin } \\
(\mathrm{mmol} / \mathrm{l})\end{array}$ & $\begin{array}{c}\text { Change } \\
\text { relative to } \\
\text { the control } \\
(\%)\end{array}$ & $\begin{array}{c}\text { Change relative } \\
\text { to MSG group } \\
(\%)\end{array}$ \\
\hline $\begin{array}{c}\text { Control } \\
\text { (distilled water } 2 \mathrm{ml} / \\
\mathrm{kg} \mathrm{b.w)}\end{array}$ & $3.49 \pm 0.37$ & 0 & -31.29 \\
\hline MSG (8 g/kg b.w) & $5.08 \pm 0.11$ & 45.56 & 0 \\
\hline Extract $(300 \mathrm{mg} / \mathrm{kg} \mathrm{b.w})$ & $3.68 \pm 0.17$ & 5.44 & -27.56 \\
\hline $\begin{array}{c}\text { MSG }(8 \mathrm{~g} / \mathrm{kg} \mathrm{b.w}+ \\
\text { Extract } \\
200 \mathrm{mg} / \mathrm{kg} \mathrm{b.w})\end{array}$ & $3.84 \pm 0.09$ & 10.03 & -24.41 \\
\hline $\begin{array}{c}\text { MSG }(8 \mathrm{~g} / \mathrm{kg} \mathrm{b} . \mathrm{w})+ \\
\text { Extract } \\
400 \mathrm{mg} / \mathrm{kg} \mathrm{b.w})\end{array}$ & $3.07 \pm 0.12$ & -12.03 & -39.57 \\
\hline
\end{tabular}

Value presented as mean \pm SEM of sample size, $n=4$ rats. + denotes higher by; - denotes lower by. Significant difference at $\mathrm{p}<0.05$

Table 4: Effect of M. indica (mango) seed kernel extract on the serum creatinine concentration (mmol/l) of normal and monosodium glutamate-intoxicated rats

\begin{tabular}{|c|c|c|c|}
\hline Groups & $\begin{array}{c}\text { Creatinine } \\
\text { (mmol/l) }\end{array}$ & $\begin{array}{c}\text { Change } \\
\text { relative to } \\
\text { the control } \\
(\%)\end{array}$ & $\begin{array}{c}\text { Change } \\
\text { relative to } \\
\text { MSG group } \\
(\%)\end{array}$ \\
\hline Control & $1.32 \pm 0.17$ & 0 & \multirow[b]{2}{*}{-40.00} \\
\hline $\begin{array}{c}\text { (distilled water } 2 \mathrm{ml} / \mathrm{kg} \\
\text { b.w) }\end{array}$ & & & \\
\hline MSG (8 g/kg b.w $)$ & $2.20 \pm 0.16$ & 66.67 & 0 \\
\hline Extract $(300 \mathrm{mg} / \mathrm{kg}$ b.w $)$ & $1.75 \pm 0.12$ & 32.58 & -20.45 \\
\hline $\begin{array}{c}\text { MSG (8 g/kg b.w + Extract } \\
200 \mathrm{mg} / \mathrm{kg} \mathrm{b.w})\end{array}$ & $1.78 \pm 0.19$ & 34.85 & -19.09 \\
\hline $\begin{array}{c}\text { MSG ( } 8 \mathrm{~g} / \mathrm{kg} \mathrm{b.w}+\text { Extract } \\
400 \mathrm{mg} / \mathrm{kg} \mathrm{b.w})\end{array}$ & $1.66 \pm 0.33$ & 25.76 & -25.55 \\
\hline
\end{tabular}

Value presented as mean \pm SEM of sample size, $n=4$ rats. + denotes

higher by; - denotes lower by. Significant difference at $\mathrm{p}<0.05$
Photomicrographs from sections of the kidney collected from the animals in the control group showed the normal renal histoarchitecture for laboratory rats. The sections showed normal Glomeruli (G) in their Bowman's capsules (arrow) embedded in a framework of normal renal tubules (proximal convoluted tubules, distal convoluted tubules, pars recta and collecting ducts) and normal renal interstitium, renal tubules (T) (Plate 1). Sections of the kidney collected from the rats exposed to MSG (8 $\mathrm{g} / \mathrm{kg}$ b.w) showed a mild to moderate multifocal degeneration of the renal tubular epithelial cells (arrow) in the cortex and inner medulla. Affected tubular epithelial cells have numerous clear cytoplasmic vacuoles. Also, multifocal areas of intense infiltration of the interstitium by inflammatory mononuclear leucocytes were observed (Plate 2).

Sections of the kidney collected from the rats in the extract $(300 \mathrm{mg} / \mathrm{kg}$ b.w) group showed the normal renal histo-architecture for laboratory rats. The sections showed normal Glomeruli $(G)$ in their Bowman's capsules embedded in a framework of normal renal tubules (proximal convoluted tubules, distal convoluted tubules, pars recta and collecting ducts) and normal renal interstitium, renal tubules (T) (Plate 3). Sections of the kidney collected from the rats in the MSG $(8 \mathrm{~g} /$ $\mathrm{kg} \mathrm{b.w}$ ) plus extract ( $200 \mathrm{mg} / \mathrm{kg}$ b.w) group showed a mild to moderate multifocal degeneration of the renal tubular epithelial cells (Black arrow) in the cortex and inner medulla. Compare with the normal tubules (white arrow)), Glomerulus (G); Affected renal tubules (T) (Plate 4).

Sections of the kidney collected from the rats in the MSG (8 $\mathrm{g} / \mathrm{kg} \mathrm{b.w}$ ) plus extract (400 $\mathrm{mg} / \mathrm{kg} \mathrm{b.w}$ ) group, just as observed above, showed a mild to moderate multifocal degeneration of the renal tubular epithelial cells (Black arrow) in the cortex and inner medulla. Affected cells are swollen and show multiple cytoplasmic vacuoles. Compare with normal tubules (white arrow). Glomerulus (G); Affected renal tubules (T) (Plate 5).

\section{Discussion}

The M. indica (mango) seed kernel, usually discarded along with the seed after consuming the fleshy part of the fruit, could contain dietary minerals and vitamins and could affect food condiment-induced adverse effects in animals. Thus, this study investigated some minerals and antioxidant vitamins in Mangifera indica (mango) seed kernel and the effects of the ethanol extract of the seed kernel on kidney histology and some kidney bio-functions of normal and monosodium glutamate (MSG) challenged rats. The study revealed the preponderance of the determined minerals and antioxidant vitamins although sodium $(390.96 \mathrm{mg} / 100 \mathrm{~g}$ ) was higher than the other determined minerals and antioxidant vitamins in the M. indica seed kernel followed by vitamin C $(377.66 \mathrm{mg} / 100 \mathrm{~g})$. The result suggests that M. indica seed kernel could be a good dietary source for these minerals and antioxidant vitamins which are of physiologic importance [30,31].

The iron content $(90.66 \mathrm{mg} / 100 \mathrm{~g})$ in the Mangifera indica seed kernel was higher than, hence not comparable with, that (11.90 mg/100 g) reported by Fowomola [15] but for mango (M. 
Indica) whole seed. Generally, minerals reported here (sodium, zinc and iron) were higher than the corresponding value reported by Yatnatti et al. [14] but for Totapuri variety of Mangifera indica. These may be related to the mango variety used and/or whether

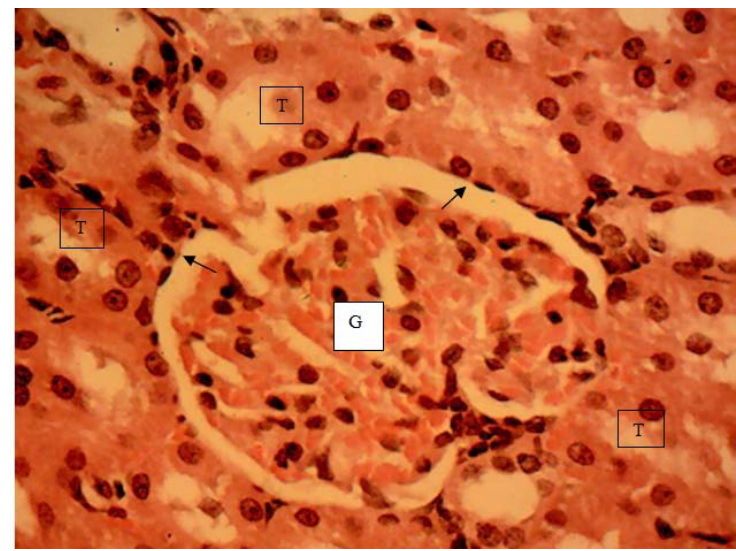

Plate 1: Photomicrograph of sections of kidney of the rats in the control group showing normal renal histo-architecture for normal rats. H\&Ex400

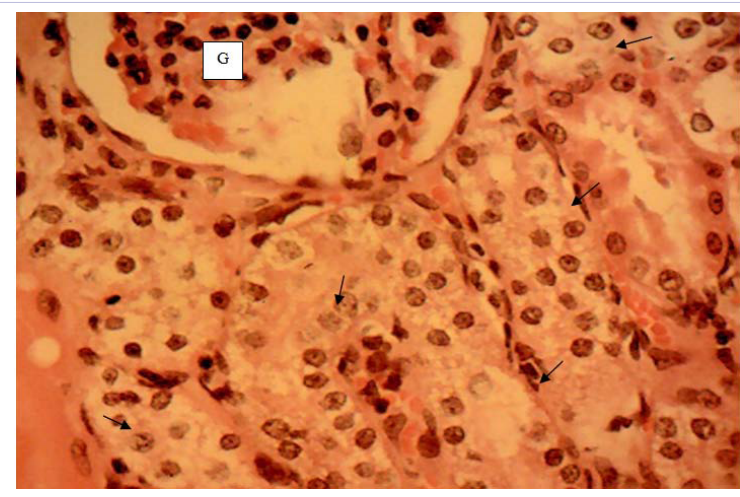

Plate 2: Photomicrograph of sections of kidney of the rats in the MSG $(8 \mathrm{~g} / \mathrm{kg}$ b.w) group showing a mild to moderate multifocal degeneration of the renal tubular epithelial cells (arrow) in the cortex and inner medulla. H\&Ex400.

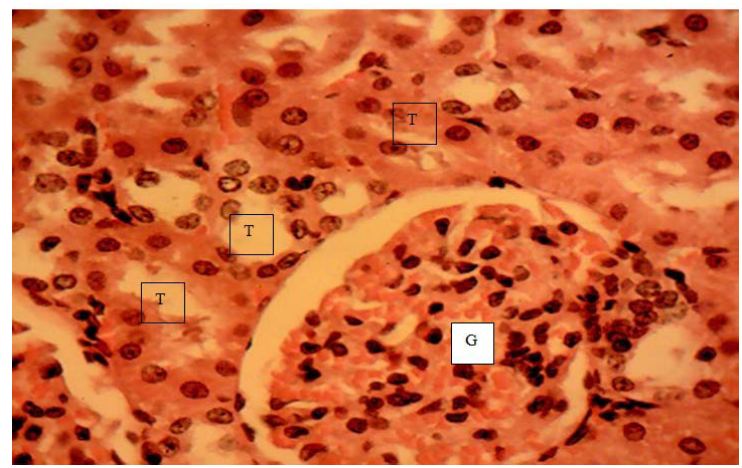

Plate 3: Photomicrograph of sections of kidney of the rats in the Extract (300 mg/kg b.w) group showing the normal Glomeruli (G) in their Bowman's capsules and normal renal tubules (T) indicative of normal renal histo-architecture for laboratory rats. H\&Ex400.

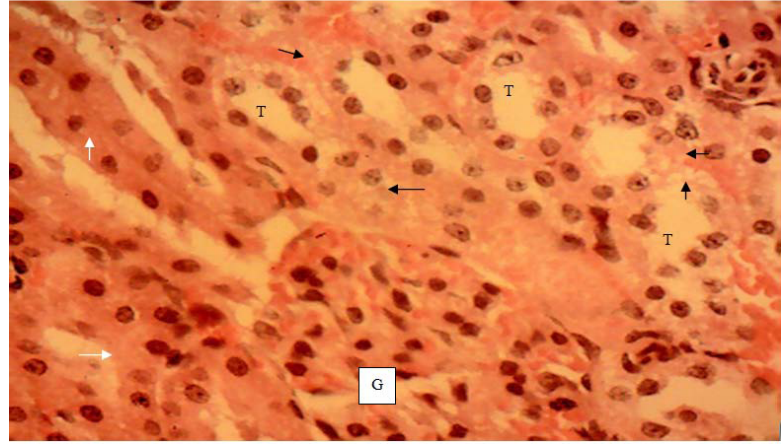

Plate 4: Photomicrograph of sections of kidney of the rats in the MSG (8 g/kg b.w) plus extract ( $200 \mathrm{mg} / \mathrm{kg} \mathrm{b.w}$ ) group showing mild to moderate multifocal degeneration of the renal tubular epithelial cells (Black arrow) in the cortex and inner medulla H\&Ex400.

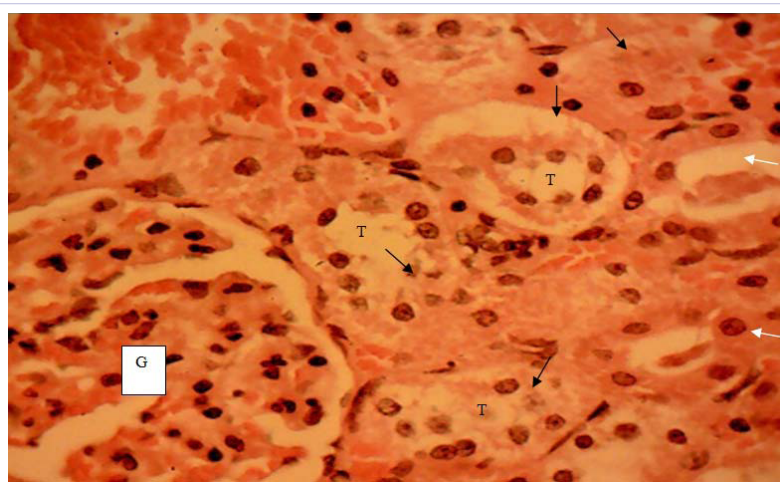

Plate 5: Photomicrograph of sections of kidney of the rats in the MSG (8 g/kg b.w) plus extract ( $400 \mathrm{mg} / \mathrm{kg}$ b.w) group showing mild to moderate multifocal degeneration of the renal tubular epithelial cells (Black arrow) in the cortex and inner medulla. Affected cells are swollen and show multiple cytoplasmic vacuoles (T). H\&Ex400.

the whole seed was used. Mango seed comprises the outer hard part and the inner tender part (kernel). The present study used the German variety and only the kernel part of mango seed. In particular, aside difference in variety, such variation in the minerals of Mangifera indica seed kernels could be due to soil type and prevailing environmental conditions [14].

Zinc and iron contents (Table 1) were quite higher than the range $1.25-10.13 \mathrm{mg} / 100 \mathrm{~g}$ and $4.63-7.08 \mathrm{mg} / 100 \mathrm{~g}$ respectively recorded in Citrullus lanatus rind and seed [32]. Sodium in the sample (Table 1 ) was higher than the range 0.33 - $19.44 \mathrm{mg} / 100 \mathrm{~g})$ for seeds and peels [33], (4.10 - $7.73 \mathrm{mg} / 100$ g) for stem, leaf and fruit of tomato and garden egg [34 Citrus sinesis] and (7.01 - $7.74 \mathrm{mg} / 100 \mathrm{~g}$ ) for Amaranthus hybridus and Telfairia occidentalis leaves [35]. Vitamin C in the sample was higher than that reported for Citrus sinesis peels and seeds [33] and the range (2.23 - 12.97) obtained for stem, leaf and fruit of tomato and garden egg [34]. Vitamin A content in the study sample $((18.94 \mathrm{mg} / 100 \mathrm{~g})$ was below the range $(56.00-267.33$ $\mathrm{mg} / 100 \mathrm{~g}$ ) recorded for stem, leaf and fruit of tomato and garden egg [34] and the value (85.71 $\pm 0.63 \mathrm{IU})$ in Citrus sinensis peels [33], but compared with that in the seeds (22.51 IU) of Citrus 
sinensis [33]. Vitamin C (ascorbic acid) is a potent antioxidant that aside facilitating the transport and uptake of non-heme iron prevents blood capillaries fragility, gum decay and scurvy [36].

Possible nephroprotective effect of MSG at low concentration was reported earlier [37]. However, several other studies reported adverse effects of higher concentration of MSG on the kidney [5-7]. In the present study, MSG at $8 \mathrm{~g} / \mathrm{kg}$ body weight compromised the rats' kidneys in support of earlier study [8] and as indicated by the lesions on the kidney and higher $(p<0.05)$ urea, albumin and creatinine concentrations in the MSG group compared to the control and the other groups. The urea concentration in the rats exposed to the extract alone was higher $(\mathrm{p}<0.05)$ than that in the control and in the rats exposed to MSG together with higher extract concentration. A similar trend was recorded for albumin and creatinine concentrations in the rats. Furthermore, the observation on these kidney function parameters (serum urea, albumin and creatinine concentrations) relative to the control was highest in the rats exposed to MSG alone and either least or even reversed in the rats exposed to MSG together with highest concentration of the extract. On the other hand, the observed change relative to the MSG group was either highest in rats in the control group followed by those in the MSG + highest extract group or vice versa. These results while paradoxical confirmed MSG-induced intoxication of the rats' kidneys, suggested apparent extract-induced adverse influence on the rats' kidneys and indicated that the extract at higher dose apparently interacted with MSG to reduce the respective MSG and extract-induced effects on the rats' serum urea, creatinine and albumin concentrations. Higher serum urea and creaatinine concentrations suggested impaired kidney functions, depletion of intracellular arginine concentration and inhibition of protein synthesis [38], and impaired functional capacity of the kidneys to filter fluids [39].

The rats' kidney histology was assessed to collaborate the serum chemistry results [40-42]. The kidney histology of rats fed M. indica seed kernel extract at $300 \mathrm{mg} / \mathrm{kg}$ body weight was comparable to that of the control group, a pointer that the observed higher serum urea, albumin, creatinine concentrations in the rats fed the extract alone at the tested concentration did not elicit definitive adverse effects on the rats' kidneys histology. As expected, the lesions in the kidney histology of rats in the MSG group on comparison with those in the control, extract and MSG + extract groups confirmed a definite MSG-related intoxication of the rats' kidneys. However, the lesions observed in the MSG plus extract co- treated groups were milder than that in the MSG group indicating extract-related mitigation of MSG-induced adverse effects on the rats' kidney histology. This is supported by the dose dependent effects of the extract on MSG-intoxication as shown in the serum chemistry results, confirming that at a higher concentration the extract sufficiently protected the rats' kidney from MSG-intoxication.

We speculated that interactive mechanisms probably involving sodium and the antioxidant vitamins in the mango seed kernel could explain the paradoxical responses of mango seed kernel. For instance, the high sodium content in the M. indica seed may explain its similar effect on the serum kidney function parameters as the MSG group, suggesting that like MSG its intoxication among other possible mechanisms may be via the release of free sodium ion. Further to this, the high vitamin C content, a potent antioxidant, in the $\mathrm{M}$. indica seed may explain the apparent capacity of M. indica seed kernel to mitigate the MSG-intoxication in the rats' kidney. Manal and Nawal [6] reported that vitamins C and E ameliorated MSG-induced adverse effects on rats' kidney functions. Also, vitamin $\mathrm{C}$ given simultaneously with MSG for 14 days protected against MSGinduced toxic effects in male albino rats [43]. Further studies are thus warranted as the results and the discussion thereto point to the apparent fundamentality of sodium in MSG-intoxication, antioxidant vitamins-related modulation and protective potential of the higher doses of mango seed kernel extract against MSGintoxication on the rats' kidney histology and bio-functions.

In conclusion, $\mathrm{M}$. indica seed kernel containing high sodium and vitamin $\mathrm{C}$ elicited non-definite adverse effects, but dose dependently mitigated the MSG-intoxication on the rats' kidney histology and some bio-functions. Further studies are warranted to determine the interactive role(s) of sodium and vitamin $\mathrm{C}$ in (particularly at higher concentration of) the mango seed kernel on MSG-intoxicated rats' kidney. Harnessing such studies could result to beneficial use of mango seed kernel in diet and drugs thereby reducing the hitherto waste status.

\section{Ethical consideration}

This study on the evaluation of biochemical effects of mango seed kernel extract on normal and monosodium glutamateintoxicated experimental models considered and adhered to the standard ethical use of experimental animals approved by the Department of Biochemistry, Michael Okpara University of Agriculture Umudike, Nigeria.

\section{References}

1. Husarova V, Ostatnikova D. Monosodium glutamate, toxic effects and their implications for human intake: A review. JMED Research. 2013;2013(2013):1-12.. doi: 10.5171/2013.608765.

2. Egbuonu ACC, Obidoa O, Ezeokonkwo CA, Ezaeanyika LUS, Ejikeme PM. Hepatotoxic effects of low dose oral administration of monosodium glutamate in male albino rats. African J. Biotechnol. 2009a;8(13):3031-.3035. doi: 10.5897/AJB09.209.

3. Egbuonu ACC. Sub-chronic concomitant ingestion of L-arginine and monosodium glutamate improves feed efficiency, lipid metabolism and antioxidant capacity in male Wistar rats. Pakistan J Biol Sci. 2012;15(6):301-305. doi: 10.3923/pjbs.2013.301.305.

4. Diniz YS, Faine LA, Galhardi CM, Rodrigues HG, Ebaid GX, Burneiko $\mathrm{RC}$, et al. Monosodium glutamate in standard and high fiber diets: metabolic syndrome and oxidative stress in rats. Nutrition. 2005;21(6):749-755.

5. Egbuonu ACC, Ejikeme PM, Obasi NL. Monosodium glutamate: Potentials at inducing prostate pathologies in male Wistar rats. African J Biotechnol. 2010a;9(36): 5950-5954. doi: 10.5897/AJB10.635.

6. Manal ST, Nawal A. Adverse effects of monosodium glutamate on liver and kidney function in adult rats and potential protective effect of vitamins C and E. Food and Nutr Sci. 2012;3(5):651-659. doi: 104236/fns.2012.35089. 
7. Egbuonu ACC, Ejikeme PM, Obasi NL. Influence of sub-chronic oral exposure to high monosodium glutamate on some serum markers of the renal functions in male Wistar rats. African J Biochem Res. 2010b;4(9):225-228.

8. Mariyamma T, Sujatha KS, Sisilamma G. Protective effect of Piper longum Linn. on monosodium glutamate induced oxidative stress in rats. Indian J Experimental Biol. 2009;47(3):186-192.

9. Stevenson DD. Monosodium glutamate and asthma. J of Nutr. 2000;130(4S Suppl):1067S-1073S.

10.Zahedi SM, Asgarian ZS, Ersi FK, Seydi A. Evaluating marketability of ten selected cultivars of mango. Open J of Ecology. 2016;6:219-224 doi: doi.org/10.4236/oje.2016.65022.

11. Shah KA, Patel MB, Patel RJ, Parmer PK. Mangifera indica (Mango). Pharmacognosy Review. 2010;4(7):42-48. doi: 10.4103/0973-784765325.

12. Li X, Cui X, Sun X, Li X, Zhu Q, Li W. Mangiferin prevents diabetic nephropathy progression in streptozotocin-induced diabetic rats. Phytotherapy Res. 2010;24(6):893-899. doi: 10.1002/ptr.3045.

13. Kittiphoom S. Utilization of mango seed. Intl Fd Res Journal. 2012;19(4):1325-1335.

14. Yatnatti S, Vijayalakshmi D, Chandru R. Processing and nutritive value of mango seed kernel flour. Current Res Nutr and Fd Sci. 2014;2(3):1 6. doi: doi.org/10.12944/CRNFSJ.2.3.10

15. Fowomola MA. Some nutrients and antinutrients content of mango (Mangifera indica) seed. African J Fd Sci. 2010;4(8):472-476.

16. Nzikou JM, Kimboonguila A, Matos L, B Loumouamou, NPG PambouTobi, CB Ndangui, et al. Extraction and characteristics of seed kerne oil from mango (Mangifera indica). Res J of Environ and Earth Sci. 2010;2(1):31-35

17. Uttara S, Sadhana S, Anita K. Therapeutic potential of antidiabetic nutraceuticals. Phytopharmacol. 2012;2(1):144-169.

18. Egbuonu ACC. Comparative investigation of the antibacterial and antifungal potentials of the extracts of watermelon (Citrullus lanatus) rind and seed. European J. of Medicinal Plants. 2015a;9(4):1-7. doi:10.9734/ejmp/2015/18142

19. McClure DE. Clinical pathology and sample collection in the laboratory rodent. The Veterinary Clinics of North America: Exotic Anima Practice. 1999;2(3):565-590.

20. Ness RD. Clinical pathology and sample collection of exotic smal mammals. The Veterinary Clinics of North America: Exotic Animal Practice. 1999;2(3):591-620.

21. Lucas RL, Lentz KD, Hale AS. Collection and preparation of blood products. Clinical Techniques in Small Animal Practice. 2004;19(2):5562

22. Onwuka GI. Food analysis and instrumentation: Theory and practice. 1st Edition. Naphtali Prints: Lagos, Nigeria; 2005.

23. Okwu DE. Spectrophotometric method for vitamin analysis: Phytochemicals, vitamins and minerals contents of two Nigerian medicinal plants. Intl. J. Molecular Medicine and Advance Sci. 2004;1(4):375-381.

24. Okwu DE, Josiah C. Evaluation of the chemical composition of two Nigerian medicinal plants. African J Biotechnol. 2006;5(4):357-361.

25. Pearson DA. Chemical Analysis of food. 7th Edition. Churchill Livingstone: Edinburgh, London; 1976

26. Association of Official Analytical Chemist (A.O.A.C). Official Methods of Analysis of the Association of official Analytical Chemist. 15th Edition, Washington DC, 1990
27. Fawcett JK, Scott JE. A Rapid and Precise method for the Determination of Urea. Journal of Clinical Pathol. 1960;13(2):156-59.

28. Henry TJ. Clinical Chemistry Principles and Techniques. 2nd Edition, Haper and Row Publishers: New York, 1974.

29. Doumas BT, Watson WA, Biggs HG. Albumin standards and the measurement of serum albumin with bromocresol green. Clinica Chimica Acta. 1971;31(1):87-96

30.Lukaski CH. Vitamin and mineral status: effects on physical performance. Nutrition. 2004;20(7-8):632-644.

31. Pathak P, Kapil U. Role of trace elements zinc, copper and magnesium during pregnancy and its outcome. Indian J Pediatrics. 2004;71(11):1003-1005.

32. Egbuonu ACC. Comparative assessment of some mineral, amino acid and vitamin compositions of watermelon (Citrullus lanatus) rind and seed. Asian J Biochem. 2015b;10(5):230-236. doi: 10.3923/ ajb.2015.230.236

33. Egbuonu ACC, Amadi CC. Some nutritive and antifungal properties of Citrus sinensis (sweet orange) peels and seeds. American Chemical Sci. Journal. 2016;14(2):1-7. doi: 10.9734/ACSJ/2016/25647

34. Kadiri M, Ojewumi AW, Olawale SO. Minerals, vitamins and chlorophyll contents of fruits, stems and leaves of tomato and garden egg. Pakistan J Fd Sci. 2015;25(3):150-154

35. Ifesan BOT, Egbewole 00, Ifesan BT. Effect of fermentation on nutritional composition of selected commonly consumed green leafy vegetables in Nigeria. Intl J of Applied Sci and Biotechnol. 2014;2(3):291-297

36. Achikanu CE, Eze-Steven PE, Ude CM, Ugwuokolie OC. Determination of the vitamin and mineral composition of common leafy vegetables in south eastern Nigeria. Intl J of Current Microbiol and Applied Sci. 2013;2(11):347-353.

37. Egbuonu ACC, Obidoa O, Ezeokonkwo CA, Ezaeanyika LUS, Ejikeme PM. Low dose oral administration of monosodium glutamate in male albino rats may be nephroprotective. Bio-Research. 2009b;7(1):470473.

38. Egbuonu ACC, Nkwazema DC, Aloh GS. Impaired renal and cellular functions in asymptomatic petroleum depot workers in Calabar metropolis, south-south Nigeria. Scientia Agricuturae. 2016;13(1):3741. doi: 10.15192/PSCP.SA.2016.13.1.3741.

39. Egbuonu ACC, Ogbu AE, Ezeanyika LUS. Sub-chronic oral esculetin (6, 7-dihydroxy-coumarin) exposure in male Wistar rats: Effect on some serum functions and organ histology. Asian J Biochem. 2015c;10(2):67-77. doi: 10.3923/ajb.2015

40. Egbuonu ACC, Ezeanyika LUS, Ejikeme PM, Obidoa O. Histomorphologic alterations in the liver of male Wistar rats treated with l-arginine glutamate and monosodium glutamate. Res J Environ Toxicol. 2010c;4(4):205-213. doi: 10.3923/rjet.2010.205.213.

41. Egbuonu ACC, Ezeanyika LUS, Ijeh II. Alterations in the liver histology and markers of metabolic syndrome associated with inflammation and liver damage in -arginine exposed female Wistar albino rats. Pakistan J Biol Sci. 2013a;16(10):469-476. doi: 10.3923/pjbs.2013.469.476.

42.Egbuonu ACC, Ejikeme PM, Ezeanyika LUS, Obidoa O. Combined oral arginine and monosodium glutamate exposure induces adverse response on the prostate function and testis histology of rats. British J Pharmaceutical Res. 2013b;3(2):247-258. doi: 10.9734/ BJPR/2013/2172

43. Hashem HE, El-Din Safwat MD, Algaidi S. The effect of monosodium glutamate on the cerebellar cortex of male albino rats and the protective role of vitamin C (Histological and Immunohistochemical Study). J. of Molecular Histol. 2012;43(2):179-186. doi: 10.1007/ s10735-011-9380-0. 